\title{
Cavernas na Sala de Aula: Análise de uma Prática Pedagógica para o Ensino de Ecologia e Evolução a partir da Espeleologia
}

Caves in the Classroom: Analysis of a Pedagogical Practice for Teaching Ecology and Evolution from Speleology

Cuevas en el Aula: Análisis de una Práctica Pedagógica para la Enseñanza de la Ecología y la Evolución a través de la Espeleologia

Rodrigo Antônio Castro Souza Biólogo Mestre em Ecologia, UFLA, Brasil rodrigodesouzaac@gmail.com

Paulo Antônio de Oliveira Temoteo Mestrando em Educação para Ciência, FC - Unesp - Bauru, Brasil paulo.temoteo@unesp.br

Antonio Fernandes Nascimento Junior Professor Doutor do Departamento de Biologia da UFLA, Brasil antoniojunior@ufla.br 


\section{RESUMO}

Esse trabalho tem como objetivo analisar uma aula que teve como tema "Introdução à Ecologia e Evolução em Cavernas". A aula teve o intuito de compreender como Metodologias de Ensino Alternativas ao modelo tradicional contribuem para a construção de conceitos biológicos. A aula surgiu no contexto da disciplina Metodologia do Ensino de Biologia, que é ofertada para o curso de licenciatura em Ciências Biológicas da Universidade Federal de Lavras. Ao final da aula, foi pedido aos participantes que respondessem a duas questões: quais os pontos positivos da aula? quais os pontos que poderiam ser melhorados? Ao todo foram escritas oito avaliações que foram analisadas no âmbito da pesquisa qualitativa, mais especificamente utilizando a análise de conteúdos por categorias. Foram construídas 3 categorias a posteriori, sendo elas "A Imersão Lúdica no Ambiente Subterrâneo", " A Fotografia e demais materiais na Construção do Imaginário do Ambiente Subterrâneo" e "o Experimento com Grilos como Articulador de Conceitos". Diante disso, é possível destacar as potencialidades do lúdico para a construção de conceitos científicos de maneira prazerosa, os benefícios que a fotografia possui por permitir conhecer lugares sem necessariamente ir até eles e por fim, a potencialidade do experimento pedagógico como forma de proposição de hipóteses, interpretação dos fenômenos e articulação de conceitos.

PALAVRAS-CHAVE: Ensino de Biologia. Metodologia Ativa. Espeleologia.

\section{ABSTRACT}

This work aims to analyze a class with the theme "Introduction to Ecology and Evolution in Caves". The class aimed to understand how Alternative Teaching Methodologies to the traditional model contribute to the construction of biological concepts. The class arose in the context of the Biology Teaching Methodology discipline, which is offered for the undergraduate course in Biological Sciences at the Federal University of Lavras. At the end of the class, participants were asked to answer two questions: what are the positive points of the class? what points could be improved? Altogether, eight evaluations were written, which were analyzed within the scope of qualitative research, more specifically using content analysis by categories. Three categories were built a posteriori, namely "Playful Immersion in the Underground Environment", "Photography and other materials in the Construction of the Imagery of the Underground Environment" and "the Experiment with Crickets as an Articulator of Concepts". Therefore, it is possible to highlight the potential of playfulness for the construction of scientific concepts in a pleasurable way, the benefits that photography has by allowing to visit places without necessarily going to them and, finally, the potential of the pedagogical experiment as a way of proposing hypotheses, interpretation of phenomena and articulation of concepts. KEYWORDS: Biology Teaching. Active Methodology. Speleology

\section{RESUMEN}

Este trabajo tiene como objetivo analizar una clase con el tema "Introducción a la ecología y la evolución en cuevas". La clase tuvo como objetivo comprender cómo las metodologías de enseñanza alternativas al modelo tradicional contribuyen a la construcción de conceptos biológicos. La clase surgió en el contexto de la disciplina de Metodología de Enseñanza de Biología, que se ofrece para el curso de pregrado en Ciencias Biológicas en la Universidad Federal de Lavras. Al final de la clase, se les pidió a los participantes que respondieran dos preguntas: ¿cuáles son los puntos positivos de la clase? ¿Qué puntos podrían mejorarse? En total, se escribieron ocho evaluaciones, que se analizaron dentro del alcance de la investigación cualitativa, más especificamente utilizando el análisis de contenido por categorías. Se construyeron tres categorías a posteriori, a saber, "Inmersión lúdica en el entorno subterráneo", "Fotografía y otros materiales en la construcción de las imágenes del entorno subterráneo" y "Experimento con grillos como articulador de conceptos". Por lo tanto, es posible resaltar el potencial de la diversión para la construcción de conceptos científicos de una manera placentera, los beneficios que tiene la fotografía al permitir visitar lugares sin ir necesariamente a ellos y, finalmente, el potencial del experimento pedagógico como una forma de proponer hipótesis. , interpretación de fenómenos y articulación de conceptos.

PALABRAS CLAVE: Enseñanza de la biología. Metodología activa. Espeleología 


\section{INTRODUÇÃO}

A espeleologia é o campo da ciência que estuda as cavernas, desde as suas origens até os processos de transformações que ocorrem dentro destes ambientes. Tal campo da ciência abrange os âmbitos físico, químico e biológico, assim como o contexto histórico-cultural relacionado à presença destes ambientes na terra, como os artefatos arqueológicos e pinturas rupestres encontrados dentro de cavernas (CUSTÓDIO, DANTAS e PRATA, 2012). Devido a presença de características peculiares, como a ausência permanente de luz e a oligotrofia (pouca nutrição disponível) (CULVER e PIPAN, 2009) as cavernas são consideradas por muitos estudiosos como "laboratórios evolutivos", podendo apresentar uma fauna peculiar com características selecionadas para a vida dentro destes ambientes inóspitos.

Tais ambientes, também apresentam em seu interior estruturas de grande beleza cênica, tituladas de espeleotemas (ex. estalactite, estalagmite, colunas, cortinas, represas de travertino, entre outros), formados pela deposição de minerais a partir de reações químicas de dissolução e precipitação sob a rocha. Estas formações, aliadas às condições físicas (ex. escuridão e lagos subterrâneos), geram manchetes em jornais, revistas, assim como reportagens sobre esses ambientes que causam grande admiração, e conseguem intrigar todos os tipos de pessoas, como trabalhadores, alunos, pesquisadores e professores. Desta forma, trabalhar a espeleologia dentro do contexto de Ensino de Ciências se torna uma abordagem potencialmente promissora que permite explorar diversas áreas do conhecimento das ciências naturais como biologia, geografia, química, física e também das ciências humanas, na história, antropologia, arqueologia e arte.

É válido ressaltar que ainda é escasso o número de trabalhos em educação e no ensino de ciências relacionados a espelelologia. A maioria dos estudos dentro desta grande temática explora vertentes ligadas ao escotismo (MOTTA, 2001), ecoturismo (KARNOPP et al., 2007), química (MACHADO e RIBEIRO, 2010) geologia (RIBEIRO e TRAVASSOS, 2015) e bioespeleologia (COSTA; SABINO; MATOS, 2007). Entretanto, os ambientes subterrâneos permitem experiências singulares dentro de um contexto desconhecido, por isso as cavernas apresentam uma grande capacidade de instigar a curiosidade e o interesse das pessoas por assuntos relacionado a tais habitats. Dessa forma, pensar as cavernas como uma porta de entrada para o ensino de ecologia e evolução se torna possível, desde que seja utilizada uma metodologia adequada sob a mediação de profissionais bem preparados.

Além disso, dinâmicas educativas envolvendo a espeleologia contribuem para discussões em torno de temáticas de Educação Ambiental dentro do contexto abordado, e também para levar esse aprendizado para o meio social no qual os alunos e professores estão inseridos. Essa discussão permite o desenvolvimento de uma conscientização ambiental dos sujeitos, além de mostrar para os estudantes a importância de se conservar as cavernas, seus ecossistemas externos e suas respectivas biotas (FERREIRA e MARTINS, 2001). O que, por sua vez, é extremamente importante, uma vez que estes ambientes apresentam elevado grau de endemismo e espécies ainda não descritas que correm risco de extinção antes mesmo de serem conhecidas (GALLÃO e BICHUETTE, 2018). Esse é um reflexo da degradação dos ambientes 
naturais, causada, principalmente, por meio de empreendimentos mineradores, agropecuários e outros (FERREIRA et al. 2014).

Para trabalhar nessa perspectiva crítica de educação que instigue os alunos a refletirem sobre os problemas ambientais, é importante utilizar ferramentas pedagógicas igualmente críticas, uma vez que as metodologias utilizadas para o ensino de ciências em sua maioria apresentam cunho expositivo. A abordagem tradicional de ensino, mesmo possuindo um grande arcabouço teórico, não explora a participação e os conhecimentos prévios dos estudantes, tornando-os passivos, e não auxiliando no processo de ensino-aprendizagem (KRASILCHICK, 2004).

Nesse sentido, a disciplina obrigatória de Metodologia do Ensino de Biologia da grade do curso de Licenciatura em Ciências Biológicas da Universidade Federal de Lavras (UFLA), propõe aos licenciandos o desenvolvimento e o trabalho com metodologias não expositivas de ensino (também chamadas de metodologias ativas), uma vez que estas apresentam inúmeras qualidades. Entre essas qualidades podemos ressaltar o fato de que elas instigam a participação ativa dos discentes, que, a partir de seus conhecimentos prévios, constroem conceitos científicos. Além disso, as metodologias ativas de ensino colaboram para o desenvolvimento da autonomia do aluno, a problematização de sua realidade, o trabalho em equipe, a inovação e a criação do estudante para resolução de problemas. Nessa perspectiva de ensino, o estudante é visto como um sujeito ativo, estando no centro do processo educativo, dentro do qual o professor irá mediar a construção do conhecimento (DIESEL e BALDEZ, 2017).

Uma aula de campo em uma caverna pode configurar uma metodologia ativa de ensino pois quando a caverna tem seu acesso permitido, ela se torna um excelente local para se desenvolver atividades relacionadas a Ecologia e Evolução em ambientes subterrâneos. No entanto, as aulas de campo em cavernas são muitas vezes inviáveis de serem realizadas por motivos como: a falta de verba para transporte, a inviabilidade da caverna de comportar muitas pessoas, cavernas distantes dos locais de vivencia dos estudantes e também a necessidade de capacitação prévia. Nesse sentido, entendemos que o ambiente cavernícola pode ser acessado por meios lúdicos, auxiliados por objetos que são próprios da caverna. Esta é uma prática que não substitui a experiência única de visitar uma caverna, mas exercita nos discentes habilidades mentais como a imaginação, que aumenta o entusiasmo e prende a atenção do estudando, além de possibilitar um ensino mais significativo, pois emula informações de diferentes formas, estimula diversos sentidos, isso tudo sem se tornar uma aula cansativa (FALKEMBACK, 2007).

Santos (2014) atenta que o uso do lúdico nas aulas pode ser um recurso "inovador" para os alunos, mas demanda que os profissionais da educação tenham objetivos claros a serem cumpridos para, assim, não perderem o sentido educativo da atividade. Esse é um dos motivos pelo qual muitos educadores, erroneamente, abrem mão deste poderoso recurso educativo, justamente por terem a apreensão de que seus alunos se dispersarão mais ainda.

Em razão do que foi apresentado, esse trabalho tem como objetivo analisar uma metodologia de tema de Introdução à Ecologia e Evolução em Cavernas, desenvolvida durante a disciplina de Metodologia do Ensino de Biologia, com o intuito de compreender como metodologias de ensino alternativas ao modelo tradicional contribuem para a construção de conceitos biológicos. Além disso, visa-se compreender como a disciplina contribuiu no processo de formação inicial de professores. 


\section{DESENVOLVIMENTO DO TRABALHO}

\subsection{Proposta da Disciplina}

A disciplina de Metodologia do Ensino de Biologia é ofertada no curso de Licenciatura em Ciências Biológicas da UFLA. Nessa disciplina, os licenciandos são instigados a desenvolverem aulas com metodologias alternativas ao modelo expositivo de ensino. Assim, a disciplina visa desenvolver a identidade docente dos alunos ao aliar os conhecimentos pedagógicos aos conteúdos biológicos. A proposta de trabalho no primeiro semestre de 2019 foi instigar os licenciandos a, individualmente, desenvolverem aulas de 50 minutos com metodologias ativas, sobre temáticas relacionadas às suas respectivas áreas de pesquisa na universidade. Após sua elaboração, as metodologias deveriam ser apresentadas ao professor, colegas e integrantes do Laboratório de Educação Científica e Ambiental (LECA) com intuito de aprimorá-las antes de sua ministração para os colegas da própria disciplina.

Nesse sentido, este trabalho visa analisar uma dessas aulas que teve como tema a "Introdução à Ecologia e Evolução em Cavernas", uma vez que o licenciando responsável por esta aula se encontrava realizando o mestrado na área de Ecologia de Ambientes Subterrâneos. A aula teve como objetivo introduzir noções básicas sobre cavidades naturais subterrâneas; construindo com os alunos conceitos referentes às interações ecológicas e adaptações evolutivas dos seres vivos neste ambiente, buscando, dessa forma, evidenciar como o ambiente cavernícola funciona como um filtro ambiental para a colonização e evolução de espécies.

\subsection{Descrição da Prática Pedagógica}

A aula foi dividida em 5 momentos: Preparação, Exploração da Caverna; Problematização da Aventura; Experimento Pedagógico; Avaliação. Na preparação, foi perguntado aos estudantes se eles sabiam o que era uma caverna, se já haviam ido em uma, e como foram suas experiências, destacando o que Ihes chamou mais atenção. Em seguida eles foram convidados a participar de uma grande aventura em uma caverna, mas antes da aventura começar, foram levados para os discentes, alguns materiais indispensáveis para iniciar a jornada, como: lanterna, capacete, câmera e um mapa.

A caverna que os alunos iriam visitar tinha como nome "Lapa Sem Fim", em que o significado desse nome foi problematizado. Nesse sentido, foi feita uma breve contextualização histórica e geológica da caverna (AULER et al., 2019). Logo em seguida, os estudantes foram questionados porque precisariam do mapa dessa caverna. Após as respostas, foi colocado para os estudantes que como não seria possível ir na caverna naquele momento, um pedacinho da caverna "Lapa Sem Fim" iria até eles por meio de fotografias e potes com algumas amostras. Esses potes conteriam formas de vida singulares, que caso fossem encontradas no meio do caminho, seriam examinadas de perto. 0 primeiro momento é ilustrado pela Figura 1.

Figuras 1: (A-D) Primeiro Momento da Aula 

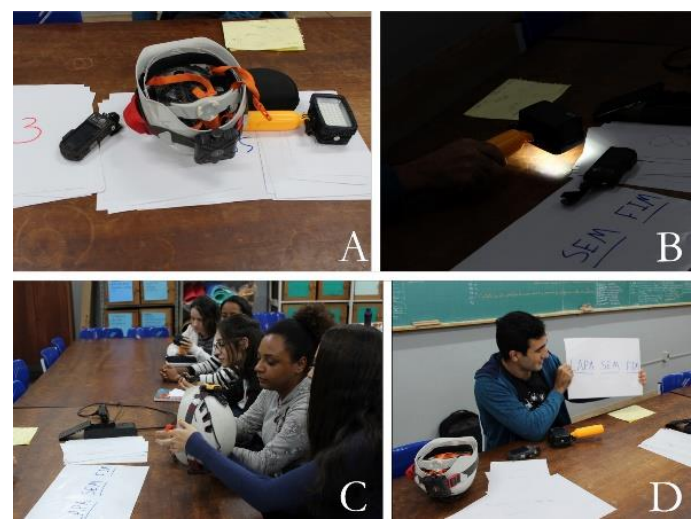

Fonte: Autores, 2019.

No segundo momento da aula, foi exibido um mapa impresso em folha A3 (FIGURA 2), que possuía 3 tipos de pontos com diferentes colorações (azul, vermelho e preto) e números. 0 mapa também apresentava medidas de temperatura e umidade das zonas de entrada, mediana e regiões mais profundas da cavidade. Estas regiões eram respectivamente representadas pelas cores roxo, vermelho e amarelo.

Figuras 2: Mapa trabalhado na aula

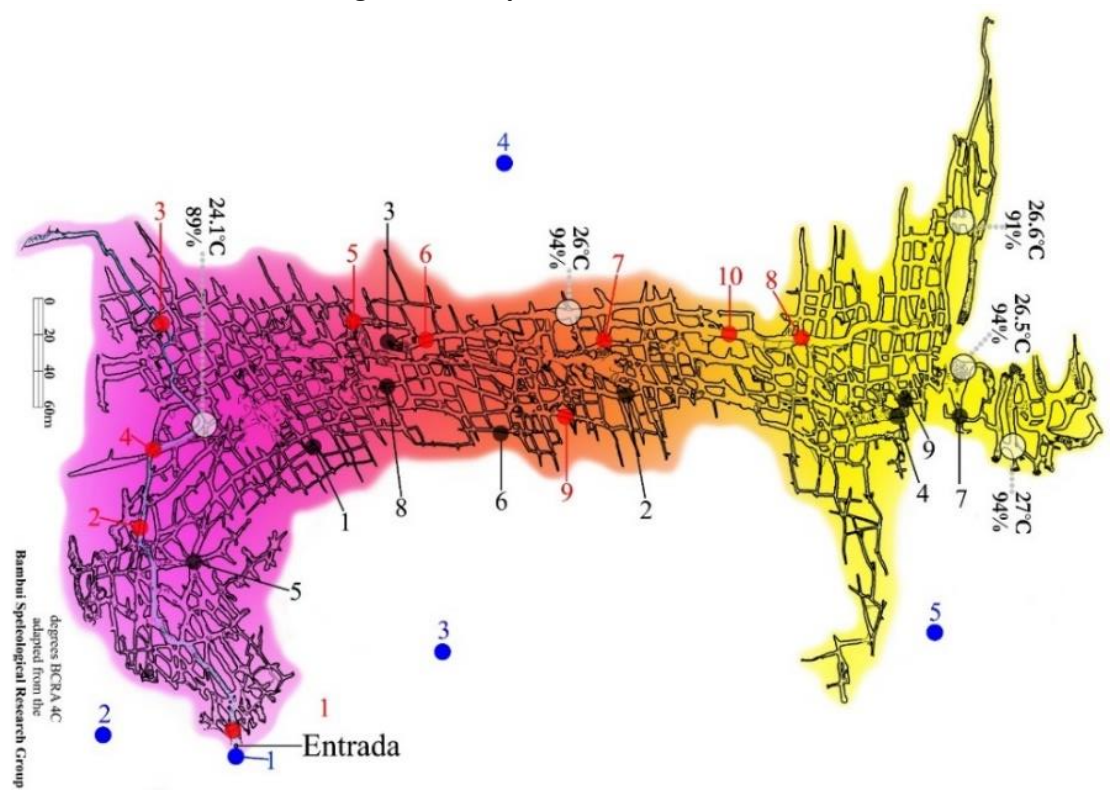

Fonte: Bambui Speleological Research Group, 2012.

Os alunos foram convidados a escolher lugares que tinham curiosidade em explorar no mapa (ex. ponto em azul, número 3), sendo que cada um dos pontos tinha uma fotografia correspondente que representava características peculiares da caverna ou do ambiente de superfície. À medida que os pontos e suas fotografias correspondentes eram escolhidos pelos alunos, eram feitas problematizações acerca das suas características.

Os pontos em azul representavam regiões e seres vivos que ocorriam nos arredores da caverna. Estes pontos, quando escolhidos, resultavam em problematizações sobre a presença de organismos produtores primários e organismos consumidores primários da cadeia trófica. 
Os pontos em vermelho representavam as condições físicas da caverna (ex. espeleotemas, condutos e ausência permanente de luz), assim como recursos alimentares que eram encontrados dentro destes ambientes (ex. guano e matéria orgânica carreada pela água). Quando esses pontos eram escolhidos eram colocadas questões como: se não há luz dentro da caverna como os animais conseguem se orientar? Como os animais vivem na escuridão? Se não existe fotossíntese como os animais se alimentam?

Os pontos em preto representavam alguns dos animais que poderiam ser encontrados dentro do ambiente subterrâneo, abrangendo diferentes níveis tróficos como os detritívoros (piolho de cobra), onívoros (grilos) e predadores (aranhas e amblipígio). A partir dessas fotografias, foi problematizado o tipo de alimento que os animais consumiam e suas respectivas interações ecológicas. Ademais, foi problematizado o fato de que algumas destas espécies de animais representavam formas de vida que sofreram pressão seletiva do ambiente subterrâneo e que, portanto, exibiam adaptações selecionadas para o modo de vida neste ambiente, neste caso em específico, adaptações morfológicas, tituladas na literatura de troglomorfismos (CHRISTIANSEN 1962; PRICOP e NEGREA, 2009).

Nesse sentido, as problematizações realizadas no segundo momento foram feitas de modo a construir conhecimentos sobre as características ecológicas e evolutivas específicas das formas de vida que vivem dentro do ambiente cavernícola (ex. perda de pigmentação, alongamento de apêndices, redução do exoesqueleto em artrópodes e perda de visão).

O terceiro momento da aula (FIGURA 3) baseou-se na realização de novas problematizações aos alunos após a "aventura" que aconteceu dentro da caverna. Estas problematizações versavam sobre a evolução dos seres vivos dentro das cavernas em paralelo com os seres vivos e suas interações no ambiente de superfície. Nesse sentido, foram realizadas perguntas como: "Um cachorro conseguiria viver dentro da caverna? Uma vaca? Um cavalo? Um passarinho? Que animal poderia viver dentro da caverna então? Um gato, um boi, ou um grilo? Por que um grilo conseguiria viver dentro de uma caverna? Observem esse grilo, será que nós conseguimos listar características que ele poderia usar para viver dentro da caverna? O que é importante para se viver em uma caverna?" Entre outras perguntas. Assim, as problematizações levaram ao entendimento de que a caverna funciona como um Filtro Ambiental que representa, ao mesmo tempo, a Seleção Natural atuando na caverna. 
Figuras 3: (F-I) Segundo momento da Aula
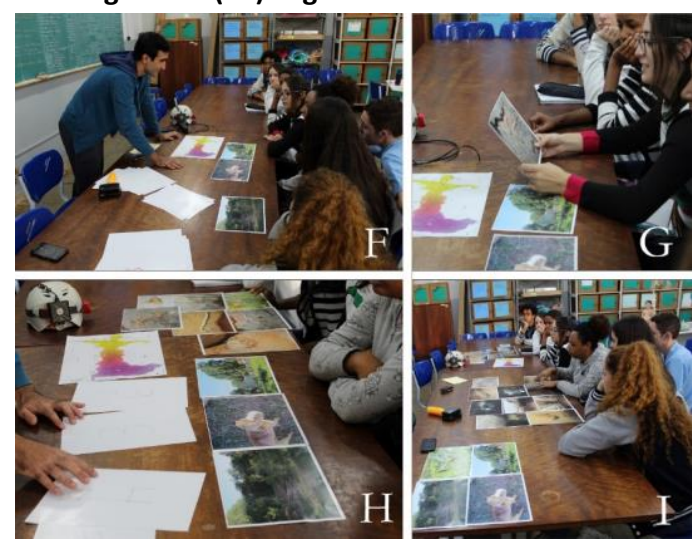

Fonte: Autores, 2019.

No quarto momento da aula, foi realizado um experimento em que foram levados para os alunos duas espécies diferentes de grilos do gênero Endecous spp., sendo uma restrita ao modo de vida subterrâneo, ou seja, que só ocorre dentro de caverna(s), e outra da superfície, mas que também pode colonizar cavernas. Nesse sentido, foi questionado aos alunos se eles conseguiam ver diferenças morfológicas entre estes grilos (FIGURA 4). Depois, os grilos foram retirados de dentro dos potes, e foi pedido para que um dos alunos movesse as mãos em frente ao campo de visão de cada um dos grilos. Ocorrendo que o grilo da caverna permaneceu imóvel e o outro grilo de vida não restrita a caverna se moveu. 0 mesmo fato também acontecia quando estas duas espécies eram expostas à iluminação artificial (FIGURA 4). Assim, foram problematizadas questões como: o grilo cavernícola ser cego, um deles ser despigmentado e o outro não, e o que o isolamento dentro das cavernas pode gerar nas populações de invertebrados. Essas e outras questões foram colocadas a fim de dar continuidade à construção dos conhecimentos desenvolvida nos momentos anteriores.

Figura 4: (J-M) Observação da morfologia dos grilos
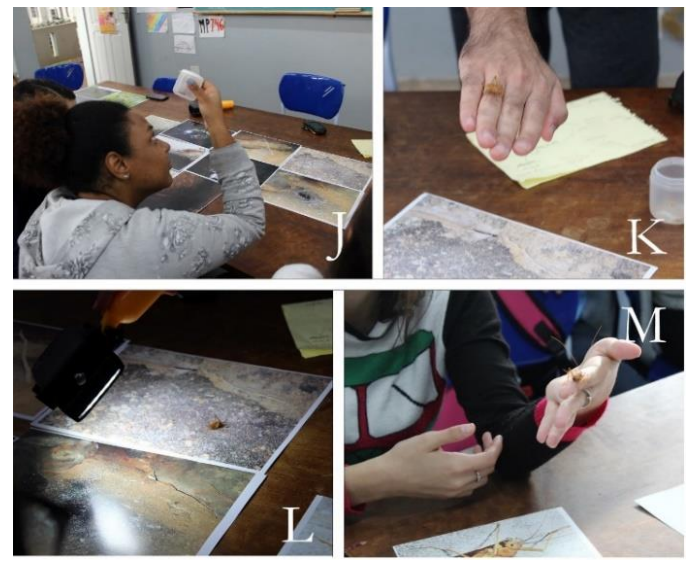

Fonte: Autores, 2019.

Ao final da aula, a partir do que foi discutido e apresentado, foi pedido aos alunos que individualmente realizassem um desenho que representasse uma caverna, com suas condições 
ambientais e com suas possíveis formas de vida específicas. Além disso, os alunos poderiam desenhar também o que tinha mais lhe chamado a atenção ao longo da aula.

\section{MÉTODO DE ANÁLISE}

Após a aula, foi pedido para que os licenciandos que participaram da aula, avaliassem de maneira escrita a prática educativa, respondendo a duas questões: "Quais os pontos positivos da aula?" "Quais os pontos que poderiam ser melhorados?"' Ao todo foram escritas 8 avaliações que serão o objetivo de análise deste trabalho.

O processo de análise deste trabalho se encontra no âmbito da Pesquisa Qualitativa, pois nesse tipo de pesquisa em educação, "a preocupação com o processo é muito maior do que com o produto. [...] O "significado" que as pessoas dão às coisas e à sua vida são focos de atenção especial do pesquisador." (LÜDKE E ANDRÉ, 1986, p. 12).

No contexto da Pesquisa Qualitativa tomamos como técnica analítica a Análise de Conteúdo por Categorias proposta por Bardin (2011), em que as frases (nossa unidade analítica) são agrupadas em categorias que apresentam ideias, sentidos e significados em comum.

\section{RESULTADOS E DISCUSSÕES}

A partir da análise das avaliações, considerando a metodologia proposta, foram construídas 3 categorias. A seguir, serão discutidas as categorias por meio do referencial teórico assumido. Para colaborar no entendimento da discussão, as categorias serão exemplificadas por falas que as compõem. Com o intuito de preservar o anonimato dos avaliadores, seus nomes serão substituídos pela letra "E" e um número correspondente.

\subsection{A Imersão Lúdica no Ambiente Subterrâneo}

Nessa categoria, são agrupadas as 7 falas que ressaltam como a metodologia, por meio de sua dinâmica, criatividade e abordagem do professor, colaboraram para a imersão lúdica dos alunos no ambiente subterrâneo. Tal sentido pode ser visto em algumas das frases que compõem a categoria:

E1 - "Pontos positivos: Aula com grande participação dos alunos, conseguiu mostrar como é um ambiente cavernícola mesmo eu nunca estando em um. [...]"

E5 - "Pontos positivos: As fotografias utilizadas na aula foram muito bem aproveitadas, de modo que quem nunca visitou uma caverna, conseguisse se sentir em uma e entendesse como funciona a vida dentro daquele ambiente. [...]"

E6 - "Pontos positivos: A aula foi muito boa teve a interação dos alunos, trouxe o espirito investigativo para a sala; conseguiu trazer como é uma caverna para dentro da sala de aula [...]" E8 - "Pontos positivos: [...] Utilização de metodologia que cativou o aluno, com o uso de imagens ilustrativas, equipamentos e afins; Boa dinâmica escolhida, possibilitando uma grande 
participação dos alunos, e sua interação com o professor; Diálogo sobre o tema de forma "fácil" compreensivo para os alunos entenderem da melhor forma; [... $]^{\prime \prime}$

Segundo Santos (2010, p. 18), a palavra "lúdico" deriva da palavra latina ludere cujo sentido denota: "ilusão, simulação, atividades que envolvam a imaginação, sonhos, desenvolvimento das capacidades de compreensão e desenvolvimento". Entendemos que a aula, ao criar uma "atmosfera" de simulação do ambiente subterrâneo, colaborou para que os alunos tivessem um melhor aprendizado, uma vez que ao trabalhar com o lúdico, é favorecido o processo de descoberta de maneira prazerosa. Deste modo, colabora para o desenvolvimento afetivo, o convívio social e a evolução das operações mentais (SANTOS, 2010).

A criação de uma situação imaginária é algo que deve ser valorizado na educação, pois é através dela que os alunos, espontaneamente, irão separar o significado do objeto, desenvolvendo assim, uma definição funcional dos conceitos, dando concretude as palavras. Esse é um exercício essencial para o desenvolvimento cognitivo e conceitual, valioso, tendo em vista que o aluno é levado a fazê-lo sem esforço (VIGOTSKI, 2007).

Em consonância com essas ideias, Silva, Mettrau e Barreto (2008) colocam a necessidade do professor atuar como mediador em uma atividade lúdica, criando situações problema para que os alunos se sintam motivados, seduzidos a se integrarem à aula e, assim, construir, por meio da problematização de suas próprias hipóteses e conhecimentos prévios, os conceitos científicos propostos em aula pelo professor.

Além disso, é importante considerar que, para além dos conhecimentos científicos aprendidos, as atividades lúdicas colaboram para o aprimoramento pessoal, social e cultural (SANTOS e CRUZ, 2002), uma vez que a atividade de imaginar ocorre individualmente em cada um dos alunos. Além disso, as regras, as falas, as dúvidas, hipóteses, problematizações dentre outros elementos que são trazidos durante a aula, são coletivizados e enriquecem o exercício cognitivo de cada estudante na aula.

Assim, ao se trabalhar com o lúdico pela mediação do professor, como em nossa experiência, foi oportunizado ao aluno conhecer aspectos do ambiente subterrâneo, mesmo que não o conhecendo pessoalmente, permitindo-o conhecer a biodiversidade desse local, suas características físicas, sua importância ecológica e a necessidade de preservação destes ambientes únicos.

\subsection{A Fotografia e demais materiais na Construção do Imaginário do Ambiente Subterrâneo}

Esta categoria agrupa as 7 falas que destacam como as fotografias do ambiente subterrâneo, assim como outros materiais, colaboraram para a construção da ambientação lúdica dos alunos, de maneira que foi possível construir os conceitos propostos na aula. Algumas das falas que exemplificam a categoria podem ser visualizadas a seguir:

E2 - "Pontos positivos: - A dinâmica utilizada foi criativa, o fato de ter usado fotografias para fazer comparações com o ambiente externo foi uma ótima ideia. [...]" 
E3 - "Pontos positivos: Gostei muito da aula, a ideia de trazer os equipamentos junto as fotografias foram muito interessantes. Eu me senti dentro da caverna com sua aula. [...]" E4 - "Pontos positivos: imagens tornam mais palpável o conhecimento, ver os animais e o ambiente ajuda na compreensão de suas características e suas razões de ser, foram trazidos bastantes objetos e até animais, além de se fazer as conexões entre os fatos. [...]"

E7 - "Pontos positivos: Aula bastante interativa, a turma teve bastante participação. $O$ uso de várias imagens para construir junto com os alunos o ambiente e características da caverna. [...]"

Para que aconteça um aprendizado significativo, é necessário que o professor ofereça aos alunos atividades diversas e, para tanto, ele deve conhecer e dominar uma série de técnicas, recursos e materiais para estabelecer uma metodologia diferenciada (FRIEDMANN, 1996). Deste modo, ao trazer as fotografias e outros objetos relacionados à exploração de ambientes subterrâneos, o professor conseguiu aproximar os alunos do objeto de estudo. Criando, desse modo, um contexto interessante para a construção dos conceitos introdutórios relacionados à ecologia e também à evolução.

É importante considerar que a fotografia é uma técnica que permite "congelar" um momento único. Tal técnica foi desenvolvida há cerca de 200 anos atrás e passou por diversos aprimoramentos desde então. Seu papel se tornou fundamental na história da humanidade moderna, por suas diversas aplicações em vários setores da sociedade, como por exemplo o de registro histórico, criminalístico, publicitário, científico entre vários outros (BORGES, ARANHA e SABINO, 2010). No âmbito da biologia, ela permite que os seres vivos e seus fenômenos possam ser registrados, oportunizando aos estudantes o aprimoramento da observação, por meio da verbalização em aula. Esta é uma habilidade chave na educação formal que tem como objetivo a construção de conceitos científicos (FARIA e CUNHA, 2016)

De acordo com Faria e Cunha (2016), a fotografia no ensino de ciências permite ao professor mediar a observação dos estudantes com objetivo de que eles possam identificar problemas, formular hipóteses e assim chegar a conclusões próprias sobre o que está sendo estudado. A fotografia permite aos alunos não só conhecer fatos novos, mas também perceber o que foi observado, ou seja, dar atenção a elementos que, usualmente, passariam despercebidos. Dentro do mundo fascinante e não iluminado das cavernas, a fotografia representa a luz que é levada por aquele que "vê", a um mundo onde a luz e a visão não são prioridades.

A fotografia beneficia o olhar para a realidade, o resgate da memória de acontecimentos passados e a associação desses acontecimentos com os atuais, como colocado por Augusto, Furtado e Nascimento Junior (2014) ela também possibilita viajar para vários locais, tempos e biomas mesmo em um contexto de sala de aula. No nosso caso, a fotografia colaborou, juntamente com outros materiais, para que os alunos viajassem ludicamente para o ambiente subterrâneo, dando as bases materiais para que esse local pudesse ser concebido e conceitualizado.

Nesse sentido, vemos que esta categoria está intimamente relacionada com a anterior, que revela a importância do lúdico. $E$ isso, pelo fato de a fotografia colaborar no descobrimento, na investigação, na imaginação e na construção dos conceitos, pois como bem colocado por Kossoy (2002, p. 42): “O sistema óptico da câmara não dá conta de revelar a realidade interior do que 
foi fotografado. Este não dito da fotografia, o que está para além do imediatamente revelado é material que pode ser imaginado, reconstituído e narrado por cada observador/leitor".

\subsection{O Experimento com Grilos como Articulador de Conceitos}

A presente categoria reúne as 4 falas que denotam como o terceiro momento da aula, em que houve a experimentação com os grilos, foi importante para articular os conceitos de seleção, adaptação e características ambientais para a compreensão da evolução das espécies.

Entendemos que todas as categorias estão relacionadas visto que, no momento derradeiro da aula, ao realizar um experimento em sala de aula com grilos foi possível que os alunos colocassem em prática os aprendizados dos momentos anteriores da aula. Isso aconteceu porque puderam exercer sua imaginação na proposição de hipóteses para explicar o fenômeno observado, assim como puderam, também, exercer a sua observação e análise sistemática como no momento da observação e problematização de fotografias para tentar explicar a pergunta que foi colocada pelo experimento. Tudo isso, amparado pela construção de conceitos teóricos de ecologia e evolução que estavam sendo construídos desde o início da aula. Deste modo, exemplificamos essa categoria com algumas das falas que a compõe:

E1 - "Pontos positivos: [...] A ideia de mostrar os grilos e mostrar a interação deles com a luz foi genial. [...]"

E3 - "Pontos positivos: [...] Quando você mostra os animais de fora da caverna e depois pergunta o porquê alguns não vivem dentro da caverna, isso foi interessante pois os alunos percebem que até mesmo para o ambiente cavernosos os animais tem adaptações. O ponto auge foi trazer os grilos para a sala de aula e comparar sobre a visão deles. [...]"

E4 - "Pontos positivos: imagens tornam mais palpável o conhecimento, ver os animais e o ambiente ajuda na compreensão de suas características e suas razões de ser, foram trazidos bastantes objetos e até animais, além de se fazer as conexões entre os fatos. [...]"

A experimentação em sala de aula ou experimentação didática, pode ser entendida como forma de transposição didática de conteúdos e procedimentos a fim de se atender a determinados fins do ensino. Nesse sentido, a experimentação escolar tem algumas semelhanças com o contexto científico de produção do conhecimento, mas tem como objetivo principal, ensinar. Ainda assim, a experimentação didática terá aspectos originais em relação a experimentação científica (OLIVEIRA; CASSAB e SELLES, 2012).

Segundo Lins et al. (2013), a experimentação no ensino de biologia permite que os estudantes lidem com mecanismos de aprendizado concretos, fundamentais para formação dos significados com uma participação ativa que ocorre por meio da formulação de hipóteses, manipulação de dados, proposição e escolha de critérios, bem como a interpretação de todos esses processos. É válido ressaltar que segundo Praia, Cachapuz e Gil-Pérez (2002), a experimentação tanto científica quanto escolar possuem uma variedade metodológica e epistemológica que quando transportadas para a sala de aula de maneira consciente pelo professor, colaboram para o desenvolvimento cognitivo dos alunos. Para tanto, é necessário que seja incentivado o 
confronto de ideias com os pares e a interpretação própria dos alunos sobre os fenômenos. Tudo isso, a partir de um quadro teórico definido e pela mediação consciente do professor abre assim, possibilidades para se trabalhar a natureza do conhecimento científico.

Dessa forma, a experimentação em sala de aula para o ensino de ecologia e evolução, em um contexto de vida em ambientes subterrâneos, se mostra uma oportunidade para que os alunos, ampliem suas capacidades, despertem a inquietação sobre o desconhecido, busquem explicações lógicas e razoáveis para os fenômenos da vidas, levando-os a desenvolver o pensamento crítico, julgar e tomar decisões amparadas por uma base de conhecimentos objetivos, criteriosos, testados sistematicamente e compartilhados por uma comunidade escolarizada (BIZZO, 1998).

\section{CONSIDERAÇÕES FINAIS}

Consideramos que a prática pedagógica demonstra que é possível desenvolver o aprendizado sobre Ecologia e Evolução a partir do campo de conhecimento da espeleologia, levando o ambiente peculiar de uma caverna para dentro da sala de aula a partir do lúdico, não necessitando de uma aula de campo. Ressaltamos a importância da disciplina de Metodologia do Ensino de Biologia como momento na formação inicial do licenciando em que ele poderá desenvolver sua identidade docente por meio da articulação entre os conhecimentos biológicos e os didático-pedagógicos.

Além disso, frisamos que todo o processo só foi possível por meio de uma mediação problematizadora do professor, daí a importância do conhecimento biológico e pedagógico, pois as categorias nos revelam as potencialidades do lúdico para a construção de conceitos científicos de maneira prazerosa; os benefícios que a fotografia possui ao transportar os alunos para locais desconhecidos e de difícil acesso; e o experimento pedagógico como forma de proposição de hipóteses, interpretação dos fenômenos e articulação de conceitos.

\section{AGRADECIMENTO}

Ao pesquisador Lucas Rabelo, e aos professores Marconi Silva e Rodrigo Ferreira pelas fotografias utilizadas em sala de aula. As instituições: UFLA, CAPES e FAPEMIG.

\section{REFERÊNCIAS BIBLIOGRÁFICAS}

AUGUSTO, Luiza Helena; OLIVEIRA, Laís Furtado; NASCIMENTO JUNIOR, Antônio Fernandes. Uma viagem fotográfica às regiões brasileiras como estratégia para o ensino de biomas e biodiversidade. Periódico Eletrônico Fórum Ambiental da Alta Paulista, v. 10, n. 6, 2014.

AULER, Augusto Sarreilo, RUBBIOLI, E., MENIN, D.; BRANDI, R. Histórico, ocorrência e potencial de cavernas no Brasil. In: Cavernas. Atlas do Brasil Subterrâneo. Brasília: Editora IABS, 2019.

BARDIN, Laurence. Análise de conteúdo. São Paulo: Edições 70, 2011, 229p.

BIZZO, Nélio. Ciências: fácil ou difícil. São Paulo: Ática, 1998, 144 p. 
BORGES, Marilia Dammski; ARANHA, José Marcelo; SABINO, José. A fotografia de natureza como instrumento para educação ambiental. Ciência \& Educação (Bauru), v. 16, n. 1, p. 149-161, 2010.

CHRISTIANSEN, K. Proposition pour la classification des animaux cavernicoles. Spelunca, 2, p. 75-78, 1962.

COSTA, Fábio Luis Bondezan da; SABINO Cláudia de Vilhena Schayer; MATOS, Santer Alvares. Levantamento do conhecimento prévio sobre cavernas em duas escolas particulares de Belo Horizonte, Minas Gerais. In: Congresso Brasileiro de Espeleologia, Anais do Congresso. 29, p. 81-85, 2007.

CULVER, David C.; PIPAN, Tanja. The biology of caves and other subterranean habitats. Oxford University Press, UK, 2009, 273p.

CUSTÓDIO, Rubiana Passos., DANTAS, Mário André Trindade; PRATA, Ana Paula Do Nascimento. O uso de recursos didáticos e a Espeleologia: Reflexões sobre alternativas para ensinar Ciências e Biologia. In: VI Colóquio Internacional "Educação e Contemporaneidade", Anais do Congresso. São Cristóvão, SE/Brasil, 6, p. 1-13, 2012.

DIESEL, Aline; BALDEZ, Alda Leila Santos; MARTINS, Silvana Neumann. Os princípios das metodologias ativas de ensino: uma abordagem teórica. Revista Thema, v. 14, n. 1, p. 268-288, 2017.

FALKEMBACH, Gilse A. Morgental. O lúdico e os jogos educacionais. In: Mídias na Educação. CINTED, UFRGS. 2007.

FARIA, Fabiola Cezar; CUNHA, Marcia Borin da. 'Olha o passarinho!' A fotografia no Ensino de Ciências. Acta Scientiarum. Human and Social Sciences, v. 38, n. 1, p. 57-64, 2016.

FERREIRA, J., ARAGÃO, L. E. O. C., BARLOW, J., BARRETO, P., BERENGUER, E., BUSTAMANTE, M., ... \& PARDINI, R. Brazil's environmental leadership at risk. Science, 346(6210), p. 706-707, 2014.

FERREIRA, Rodrigo Lopes; MARTINS, Rogério Parentoni. Cavernas em risco de extinção. Ciência Hoje, 29 (173): p. 20-28, 2001.

FRIEDMANN, Adriana. Brincar: crescer e aprender - o resgate do jogo infantil. Moderna, São Paulo, 1996.

GALLÃO, Jonas Eduardo; BICHUETTE, Maria Elina. Brazilian obligatory subterranean fauna and threats to the hypogean environment. ZooKeys, n. 746, p. 1, 2018.

KARNOPP, Paul. K. F.; ANDRETTA, V.; MACEDO, R. L.G.; VITORINO, M. R.; MACEDO, S. B.; VENTURINI, N. Espeleologia: um instrumento de difusão da educação ambiental em atividades ecoturísticas. Il encontro interdisciplinar de ecoturismo em unidades de conservação. Anais do Congresso. 2007.

KOSSOY, Boris. Realidades e fiç̧ões na trama fotográfica. São Paulo, Ateliê Editorial, 2002.

KRASILCHIK, Myriam. Reformas e Realidade: o caso do ensino das ciências. São Paulo: São Paulo em Perspectiva, 14, p. 85-93, 2000.

LINS, Bruno de Oliveira; SANTOS, Dalva Ferreira dos; ARAÚJO, Renato Silva; MALHEIRO, João Manoel da Silva. A experimentação no ensino de biologia: o que fazem/dizem os professores em uma escola pública de Ourilândia do Norte (PA). Educação Unisinos, v. 18, n. 1, p. 77-85, 2013.

LÜDKE, Menga, ANDRÉ, Marli E. D. A. Pesquisa em educação: abordagens qualitativas. São Paulo: EPU, 1986.

MACHADO, Raphaela Luiza; RIBEIRO, Kátia Dias Ferreira. Conhecendo as cavernas para desenvolver o conhecimento químico. XV ENEQ, 21 a 24 de julho de 2010, Brasília-DF, Anais do XV ENEQ. 2010.

MOTTA, Jose Augusto de Oliveira. A Espeleologia como Instrumento de Educação Ambiental: Parceria Escotismo X IBAMA/CECAV-GO, Um Estudo de Caso. In: 26th Brazilian Congress of Speleology, Anais do Congresso. Brasília, p. 671-673. 2001. 
OLIVEIRA, Alexandre Alberto Queiroz de; CASSAB, Mariana; SELLES, Sandra Escovedo. Pesquisas brasileiras sobre a experimentação no ensino de Ciências e Biologia: diálogos com referenciais do conhecimento escolar. Revista Brasileira de Pesquisa em Educação em Ciências, v. 12, n. 2, p. 183-209, 2012.

PRAIA, João; CACHAPUZ, António; GIL-PÉREZ, Daniel. A hipótese e a experiência científica em educação em ciência: contributos para uma reorientação epistemológica. Ciência \& Educação (Bauru), v. 8, n. 2, p. 253-262, 2002.

PRICOP, Emilian; NEGREA, Bogdan M. On the adaptations to cave life of some different animal groups. Extreme Life, Biospeology \& Astrobiology, v. 1, n. 1, 2009.

RIBEIRO, Wallace Carvalho; TRAVASSOS, Luiz Eduardo Panisset. Educação Ambiental no carste em Minas Gerais: possibilidades de ensino e aprendizagem sobre o patrimônio geológico. Revista Brasileira de Educação Ambiental (RevBEA), 10(2), p. 126-148, 2015.

SANTOS, Santa Marli Pires; CRUZ, Dulce Mesquita. O lúdico na formação do educador. 5ạ ed. Petrópolis, RJ: Vozes, 2002.

SANTOS, Simone Cardoso dos, A Importância do Lúdico no Processo de Ensino Aprendizagem. 2010. Monografia (Especialização Lato-Sensu em Gestão Educacional) Universidade Federal de Santa Maria, Santa Maria, 2010

SANTOS, Vilmar Rodrigues. Jogos na escola: os jogos nas aulas como ferramenta pedagógica. Petrópolis: Vozes, 2014.

SILVA, Alcina Maria Testa Braz da; METTRAU, Marsyl Bulkool; BARRETO, Márcia Simão Linhares. O lúdico no processo de ensino-aprendizagem das ciências. Revista Brasileira de Estudos Pedagógicos, v. 88, n. 220, 2007.

VIGOTSKI, Lev Semyonovich. A Formação Social da Mente. São Paulo: Martins Fontes, 2007. 